\title{
PEMBENTUKAN PROGRAM POS PEMBINAAN TERPADU (POSBINDU) PENYAKIT TIDAK MENULAR (PTM) DENGAN MEMANFAATKAN DANA DESA PEMERINTAH DESA NGROWO KECAMATAN BANGSAL - MOJOKERTO
}

\section{The Creating Of Integrated Center Program (POSBINDU) Non Infection Disease (PTM) Using Village Funding In Ngrowo Village Kecamatan Bangsal - Mojokerto}

\author{
Yudha Laga Hadi Kusuma ${ }^{1}$, Dwiharini Puspitaningsih ${ }^{2}$ \\ Agustin Dwisyalfina ${ }^{3}$, Elok Widayanti ${ }^{4}$ \\ ${ }^{1,2}$ Prodi D3 Keperawatan STIKes Majapahit \\ ${ }^{3}$ Prodi D3 Kebidanan STIKes Majapahit \\ Jl. Raya Gayaman KM. 02 Mojoanyar - Mojokerto \\ ${ }^{4}$ Puskesmas Bangsal Kabupaten Mojokerto \\ Jl. Raya Bangsal KM. 08 Bangsal - Mojokerto \\ Email : lagayudha@gmail.com
}

\begin{abstract}
Abstrak
Penyakit tidak menular masih menjadi penyebab kematian terbesar masyarakat pada negara berkembang dan menengah. Faktor risiko penyakit tidak menular ini dapat diminimalkan melalui upaya kesehatan berbasis masyarakat (UKBM) dengan mengaktifkan program pos pembinaan terpadu penyakit tidak menular (Posbindu-PTM). Saat ini dengan lahirnya Undang - Undang Desa yang didalamnya telah mengatur penggunaan Dana Desa, maka penyelenggaraan Posbindu-PTM di Desa dapat di biayai dengan memanfaatkan penggunaan Dana Desa.

Pengabdian masyarakat yang di lakukan Tim Pengabdian Masyarakat STIKes Majapahit bersama Tim dari Puskesmas Bangsal di Desa Ngrowo Kecamatan Bangsal Kabupaten Mojokerto ini bertujuan untuk membentuk program Posbindu-PTM dengan memanfaatkan Dana Desa yang dimiliki oleh pemerintah Desa Ngrowo. Pengapdian masyarakat ini diharapkan pada akhirnya masyarakat akan aktif dalam mengikuti program Posbindu-PTM sehingga faktor risiko penyakit tidak menular masyarakat dapat terkontrol.

Kegiatan pengabdian masyarakat ini meliputi pendidikan kesehatan pada masyarakat tentang penyakit tidak menular, upaya advokasi pada pemerintah Desa Ngrowo tentang program Posbindu-PTM, pembentukan dan pelatihan Kader serta aplikasi pelaksanaan Posbindu-PTM langsung pada masyarakat. Hasil yang didapatkan, pemerintah Desa Ngrowo mengalokasikan biaya penyenggaraan Posbindu-PTM melalui Dana Desa 2018, sebagian besar 50 orang (90\%) masyarakat memiliki antusias yang tinggi untuk mengikuti Posbindu-PTM. Masyarakat yang sukarela menjadi Kader Posbindu-PTM ada 21 orang dan pelaksanaan Posbindu-PTM dilaksanakan di 3 Dusun yang ada di Desa Ngrowo setiap satu bulan sekali pada masing - masing dusun.

Program Posbindu-PTM merupakan salah satu upaya untuk meminimalkan faktor risiko penyakit tidak menular pada masyarakat. Pembiayaan penyelenggaraan Posbindu-PTM dapat di alokasikan melalui pemanfaatan Dana Desa yang di miliki Desa sebagai bagian dari program pemberdayaan masyarakat.
\end{abstract}

Kata Kunci : Posbindu - PTM, Dana Desa

\section{PENDAHULUAN}

Penyakit Tidak Menular (PTM) utama (kardiovaskuler, kanker, diabetes mellitus, penyakit paru obstruktif kronik dan gangguan akibat kecelakaan dan tindak kekerasan) terutama di negara berkembang telah mengalami peningkatan kejadian dengan cepat sehingga berdampak pada peningkatan angka kesakitan dan kematian.
Menurut World Health Organization (2005) Penyebab kematian masyarakat terbesar (80\%) pada negara berpendapatan rendah dan menengah adalah meningkatnya angka kejadian penyakit tidak menular pada masyarakat. Faktor risiko penyakit tidak menular sangat bergantung pada perilaku atau kebiasaan hidup sehat masyarakat, karenanya pengendalian terhadap faktor 
risiko tersebut sangat mungkin dikendalikan melalui upaya kesehatan berbasis masyarakat (UKBM). Dekpkes RI (2012) upaya kesehatan untuk mengontrol faktor risiko penyakit tidak menular pada masyarakat dapat dilakukan dengan menggalakkan program kegiatan pos pembinaan terpadu penyakit tidak menular (Posbindu-PTM).

Di Indonesia berdasarkan Riset Kesehatan Dasar (Riskesdas) tahun 2007 menyatakan bahwa penyebab kematian terbesar di Indonesia untuk penduduk umur 5 tahun ke atas adalah stroke baik di perdesaan maupun di perkotaan. Selanjutnya hasil Riskesdas tersebut juga menunjukkan bahwa, berdasarkan diagnosa tenaga kesehatan, data prevalensi nasional untuk: penyakit sendi sebesar 30,3\%, Hipertensi (untuk penduduk umur 18 tahun lebih) adalah 31,7\%, Stroke $0,83 \%$, Asma 4,0\%, Kanker 0,4\%, Jantung sebesar $7,2 \%$ dan Diabetes $1,1 \%$ (pemeriksaan dengan biomedis sebesar $5,7 \%$ ), Sedangkan untuk prevalensi nasional cedera adalah $7,5 \%$ (berdasarkan pengakuan responden, untuk berbagai penyebab cedera, 25,9\% merupakan cedera karena lalu lintas darat). Data untuk faktor risiko PTM adalah Obesitas Umum sebesar 10,3\%, Obesitas Sentral 18,8\%, Toleransi Gula Terganggu (TGT) 10,2\%, Kurang makan buah dan sayur 93,6\%, Minum beralkohol 4,6\%, Kurang aktifitas fisik 48,2\%, dan Merokok 23,7\% serta prevalensi kurang aktifitas fisik untuk penduduk umur 10 tahun ke atas sebesar $48,2 \%$.

Desa Ngrowo merupakan salah satu desa yang berada di wilayah kerja Puskesmas Bangsal. Hasil dari wawancara dengan 6 masyarakat Desa Ngrowo didapatkan bahwa 4 orang diantaranya menyatakan bahwa keluarga mereka memiliki riwayat darah tinggi, aktifitas olahraga selama 30 menit minimal dua kali dalam seminggu tidak pernah dilakukan, makan sayur dua hari sekali, masakan suka asin dan dari hasil pemeriksaan keempatnya mengalami darah tinggi (hipertensi). Menurut masyarakat mereka biasa memeriksakan diri ke tenaga kesehatan jika mengalami sakit saja, mereka jarang memeriksakan kesehatan dalam bentuk cek kesehatan dalam kondisi sehat, hal ini menurut masyarakat jarang dilakukan karena letak tempat tinggal mereka jauh dari Puskesmas Bangsal. Sedangkan, upaya kesehatan berbasis masyarakat yang ada di
Desa Ngrowo masih sekedar Posyandu Balita dan Posyandu Lansia, namun kader kesehatan yang dimiliki oleh Desa Ngrowo tergolong banyak dan memiliki semangat yang lebih dalam mengembangkan kegiatan upaya kesehatan.

Berdasarkan kondisi tersebut,maka diperlukan strategi pengendalian PTM yang melibatkan peran serta masyarakat. Bentuk pemberdayaan masyarakat adalah melalui kegiatan Posbindu-PTM. Guna terlaksananya kegiatan Posbindu-PTM ini terlebih dahulu perlu dilakukan pendidikan kesehatan tentang PTM untuk meningkatkan kesadaran masyarakat tentang faktor - faktor risiko PTM, selanjutnya melakukan advokasi kepada pemerintah desa guna turut serta dalam kegiatan pengendalian faktor risiko PTM. Setelah itu barulah di adakan pelatihan Kader Posbindu-PTM sebagai bagian dari kelompok masyarakat peduli PTM yang mampu melaksanakan deteksi dini faktor risiko PTM dan tindak lanjutnya secara mandiri dan berkesinambungan. Kader kesehatan diharapkan mampu berperan aktif dalam masyarakat dan bertindak sebagai motor penggerak (agent of change) dalam pengendalian PTM. Karenanya pengabdian masyarakat ini merupakan solusi agar program Psobindu-PTM di desa ini terbentuk dan pemerintah desa mau untuk menganggarkan pembiayaan pelaksanaannya melalui pengguanaan Dana Desa.

\section{METODE}

Metode dalam pengabdian masyarakat ini menggunakan metode Participatory Learning and Action (PLA) serta advokasi.Metode PLA digunakan sebagai upaya pemberdayaan masyarakat untuk melaksanakan program Posbindu-PTM di Desa. Metode advokasi digunakan untuk mendampingi pemerintah Desa Ngrowo dalam Musyawarah Rencana Pembangunan Desa (Musrenbangdes) untuk dapat mengalokasikan biaya penyelenggaraan program Posbindu-PTM melalui Dana Desa. Tahapan kegiatan pengabdian masyarakat yang dilaksanakan Tim Pengabdian Masyarakat STIKes Majapahit yaitu, pertama pendidikan kesehatan pada masyarakat tentang penyakit tidak menular, kedua upaya advokasi pada pemerintah Desa Ngrowo tentang program Posbindu-PTM, ketiga pembentukan dan pelatihan Kader dan 
keempat aplikasi pelaksanaan Posbindu-PTM langsung pada masyarakat di masing-masing Dusun yang ada di Desa Ngrowo.

\section{HASIL}

Pengabdian masyarakat yang di lakukan oleh tim pengabdian masyarakat STIKes Majapahit dan Puskesmas Bangsal di Desa Ngrowo Kecamatan Bangsal Mojokerto pada tanggal 06 Januari s/d 19 Februari 2018 didapatkan hasil sebagai berikut :

\section{Pendidikan Kesehatan Pada Masyarakat Tentang PTM}

Kegiatan pertama yang dilakukan oleh tim adalah pendidikan kesehatan yang bertujuan untuk meningkatkan pengetahuan masyarakat tentang PTM sehingga nantinya memiliki kesadaran untuk bisa menjaga diri dari faktor risiko PTM. Pendidikan kesehatan ini dilaksanakan dalam satu hari pada tanggal Sabtu, 6 Januari 2018.

Peserta yang mengikuti pendidikan kesehatan berasal dari tiga dusun yang ada di Desa Ngrowo, yaitu dari Dusun Tawangsari, Dusun Pendowo dan Dusun Ngranggon. Karakteristik masyarakat yang mengikuti pendidikan kesehatan adalah sebagai berikut :

Tabel 1. Distribusi frekuensi peserta pendidikan kesehatan jika dilihat peran sosialnya dalam masyarakat Desa Ngrowo Kec. Bangsal - Mojokerto pada Sabtu, 6 Januari 2018

\begin{tabular}{lccc}
\hline & Karakteristik & Jumlah & Persentase (\%) \\
\hline Perangkat Desa & 7 & 15 \\
Kader Kesehatan & 15 & 33 \\
Masyarakat Umum & 24 & 52 \\
\hline Jumlah & $\mathbf{4 6}$ & $\mathbf{1 0 0}$ \\
\hline
\end{tabular}

Tabel 2. Distribusi frekuensi peserta pendidikan kesehatan masyarakat Desa Ngrowo Kec. Bangsal - Mojokerto jika ditinjau dari jenis kelamin pada Sabtu, 6 Januari 2018

\begin{tabular}{lccc}
\hline & Karakteristik & Jumlah & Persentase (\%) \\
\hline Laki-laki & 5 & 11 \\
Perempuan & 41 & 89 \\
\hline Jumlah & $\mathbf{4 6}$ & $\mathbf{1 0 0}$ \\
\hline
\end{tabular}

Tabel 3. Distribusi frekuensi peserta pendidikan kesehatan masyarakat Desa Ngrowo Kec. Bangsal - Mojokerto jika ditinjau pengetahuan sesudah mengikuti pendidikan kesehatan pada Sabtu, 6 Januari 2018

\begin{tabular}{lccc}
\hline & Karakteristik & Jumlah & Persentase (\%) \\
\hline Sangat Baik & 8 & 17 \\
Baik & 34 & 74 \\
Cukup & 4 & 9 \\
Kurang & 0 & 0 \\
Sangat Kurang & 0 & 0 \\
\hline Jumlah & $\mathbf{4 6}$ & $\mathbf{1 0 0}$ \\
\hline
\end{tabular}

2. Advokasi Pemerintah Desa Ngrowo Tentang Pembiayaan Posbindu-PTM Melalui Dana Desa

Kegiatan kedua yang dilakukan pada Senin, 8 Januari 2018, yaitu upaya advokasi kepada Kepala Desa Ngrowo berserta jajarannya untuk meyakinkan bahwa Program Posbindu-PTM ini penting dan perlu dilaksanakan. Selain itu, pembiayaan pelaksanaan program ini dapat di anggarankan melalui Dana Desa.
Langkah yang dilakukan sebelum menganggarkannya meliputi :

1. Survey tentang penyakit tidak menular yang ada di Desa Ngrowo

2. Menguatkan permasalahan dalam Musyawarah Desa

3. Menganggarkan pendanaan melalui rapat pembahasan RAPBDes

4. Mengalokasikan pembiayaan dalam penggunaan Dana Desa 
Desa Ngrowo pada tahun 2018 melalui anggaran silpa Dana Desa tahun 2017 telah menganggarkan biaya untuk penyelenggaraan kegiatan Posbindu-PTM selama satu tahun

\section{Pembentukan Dan Pelatihan Kader Posbindu-PTM}

Kegiatan ketiga pada Kamis-Senin, 25 29 Januari 2018, setelah pemerintah Desa Ngrowo menganggarkan pembiayaan program Posbindu-PTM, dilanjutkan dengan mengadakan pembentukan dan pelatihan kader Posbindu-PTM yang bersumber dari kader kesehatan Desa Ngrowo yang sudah ada. Desa Ngrowo memiliki 3 Dusun Tawangsari, Dusun Pendowo dan Dusun Ngranggon, sedangkan jumlah kader Posbindu-PTM di masing-masing Dusun adalah sebanyak 4 orang.

\section{Aplikasi Pelaksanaan Posbindu-PTM}

Kegiatan terakhir sebagai bentuk aplikasi dari hasil sosialisasi, pembentukan dan pelatihan program Posbindu-PTM maka tim pengabdian masyarakat melaksanakan Posbindu-PTM langsung kemasyarakat. Pelaksanaan Posbindu-PTM dilakukan di masing-masing Dusun yang ada di Desa Ngrowo mulai tanggal 15 - 19 Februari 2018.

Dari hasil wawancara dan pemeriksaan sederhana pada saat Posbindu-PTM didapatkan data faktor risiko PTM masyarakat sebagai berikut :

\begin{tabular}{lccccccc}
\hline \multirow{2}{*}{ Karakteristik } & \multicolumn{7}{c}{ Dusun Tawangsari } \\
\cline { 2 - 7 } & \multicolumn{2}{c}{ Normal } & \multicolumn{3}{c}{ Tidak } & \multicolumn{3}{c}{ Total } \\
\cline { 2 - 7 } & Jumlah & \% & Jumlah & \% & Jumlah & \% \\
\hline Riwayat PTM Keluarga & 24 & 69 & 11 & 31 & 35 & 100 \\
$\quad$ Darah Tinggi & 29 & 83 & 6 & & 35 & 100 \\
Kencing Manis & & & & & & \\
Riwayat PTM Sendiri & 23 & 66 & 12 & 34 & 35 & 100 \\
$\quad$ Darah Tinggi & 30 & 86 & 5 & 14 & 35 & 100 \\
Kencing Manis & 26 & 74 & 9 & 26 & 35 & 100 \\
Kolesterol & 27 & 77 & 8 & 23 & 35 & 100 \\
Asam Urat & & & & & & \\
Faktor Risiko PTM & 33 & 94 & 2 & 6 & 35 & 100 \\
Merokok & 14 & 40 & 21 & 60 & 35 & 100 \\
Makan Asin & 19 & 54 & 16 & 46 & 35 & 100 \\
Makan Sayur & 14 & 40 & 21 & 60 & 35 & 100 \\
Olah Raga & 28 & 80 & 7 & 20 & 35 & 100 \\
Ketegangan / Cemas / Stress & & & & & & \\
\hline
\end{tabular}

Tabel 5. Distribusi frekuensi karakteristik faktor risiko PTM peserta Posbindu-PTM Dusun Pendowo Desa Ngrowo Kec. Bangsal - Mojokerto, Februari 2018

\begin{tabular}{lccccccc}
\hline \multirow{2}{*}{ Karakteristik } & \multicolumn{5}{c}{ Dusun Pendowo } \\
\cline { 2 - 7 } & \multicolumn{3}{c}{ Normal } & \multicolumn{3}{c}{ Tidak } & \multicolumn{3}{c}{ Total } \\
\cline { 2 - 7 } & Jumlah & \% & Jumlah & \% & Jumlah & \% \\
\hline Riwayat PTM Keluarga & 33 & 79 & 9 & 21 & 42 & 100 \\
$\quad$ Darah Tinggi & 35 & 83 & 7 & 17 & 42 & 100 \\
Kencing Manis & & & & & & \\
Riwayat PTM Sendiri & 34 & 81 & 8 & 19 & 42 & 100 \\
$\quad$ Darah Tinggi & 40 & 95 & 2 & 5 & 42 & 100 \\
Kencing Manis & 33 & 79 & 9 & 21 & 42 & 100 \\
Kolesterol & 36 & 86 & 6 & 14 & 42 & 100 \\
Asam Urat & & & & & & \\
Faktor Risiko PTM & 41 & 98 & 1 & 2 & 42 & 100 \\
Merokok & 17 & 40 & 25 & 60 & 42 & 100 \\
Makan Asin & 19 & 45 & 23 & 55 & 42 & 100 \\
Makan Sayur & 15 & 36 & 27 & 64 & 42 & 100 \\
Olah Raga & 38 & 90 & 4 & 10 & 42 & 100 \\
Ketegangan / Cemas / Stress & & & & & & &
\end{tabular}


Tabel 6. Distribusi frekuensi karakteristik faktor risiko PTM peserta Posbindu-PTM Dusun Ngranggon Desa Ngrowo Kec. Bangsal - Mojokerto, Februari 2018

\begin{tabular}{|c|c|c|c|c|c|c|}
\hline \multirow{3}{*}{ Karakteristik } & \multicolumn{6}{|c|}{ Dusun Ngranggon } \\
\hline & \multicolumn{2}{|c|}{ Normal } & \multicolumn{2}{|c|}{ Tidak } & \multicolumn{2}{|c|}{ Total } \\
\hline & Jumlah & $\%$ & Jumlah & $\%$ & Jumlah & $\%$ \\
\hline \multicolumn{7}{|l|}{ Riwayat PTM Keluarga } \\
\hline Darah Tinggi & 31 & 82 & 7 & 18 & 38 & 100 \\
\hline Kencing Manis & 37 & 97 & 1 & 3 & 38 & 100 \\
\hline \multicolumn{7}{|l|}{ Riwayat PTM Sendiri } \\
\hline Darah Tinggi & 31 & 82 & 7 & 18 & 38 & 100 \\
\hline Kencing Manis & 37 & 97 & 1 & 3 & 38 & 100 \\
\hline Kolesterol & 33 & 87 & 5 & 13 & 38 & 100 \\
\hline Asam Urat & 37 & 97 & 1 & 3 & 38 & 100 \\
\hline \multicolumn{7}{|l|}{ Faktor Risiko PTM } \\
\hline Merokok & 38 & 100 & 0 & 0 & 38 & 100 \\
\hline Makan Asin & 23 & 61 & 15 & 39 & 38 & 100 \\
\hline Makan Sayur & 32 & 84 & 6 & 16 & 38 & 100 \\
\hline Olah Raga & 19 & 50 & 19 & 50 & 38 & 100 \\
\hline Ketegangan / Cemas / Stress & 36 & 95 & 2 & 5 & 38 & 100 \\
\hline
\end{tabular}

\section{PEMBAHASAN}

Program Posbindu-PTM masih belum banyak dikenal oleh masyarakat dibandingkan kegiatan posyandu balita atau lansia, hal ini mungkin dikarenakan Posbindu-PTM masih banyak diketahui oleh masyarakat. Untuk itu pendidikan kesehatan tentang pentingnya mengetahui sejak dini faktor risiko penyakit tidak menular melalaui Posbindu-PTM itu sangat penting untuk dilakukan. Umayana (2015) mengatakan bahwa perilaku masyarakat untuk berkunjung ke tempat layanan kesehatan seperti Posbindu-PTM di tentukan oleh tiga faktor, yang salah satunya adalah faktor predisposisi dimana pengetahuan tentang masyarakat tentang Posbindu-PTM ini memiliki peran penting. Setelah masyarakat tahu, maka masyarakat akan memiliki sikap untuk menentukan arti dari Posbindu-PTM, setelah itu akan diyakini baru mereka akan bertindak memutuskan untuk mengikuti atau melaksakan program Posbindu-PTM.

Faktor lain yang memiliki peranan dalam mengembangkan program PosbinduPTM selain motifasi dari dalam diri seseorang, faktor dari luar seperti dukungan dari lingkungan atau pengambil kebijakan dalam hal ini pemerintah desa juga sangat penting. Umaya (2015) lebih lanjut menyampaikan bahwa desa yang memiliki kepala desa dengan pemikiran pengembangan kesehatan masyarakat juga perlu dilakukan maka kegiatan PosbinduPTM di desa tersebut akan berlangsung lebih baik dibandingkan dengan desa yang kepala desanya hanya memikirkan pembangunan fisik desa saja. Upaya advokasi kepada kepala desa agar nantinya kepala desa dapat mengalokasikan anggaran yang ada di desa untuk pelaksanaan program Posbindu ini dapat dilakukan salah satunya dengan cara bersama - sama mempelajari dasar hukum yang dapat dipakai sebagai payung hukum dalam penggunaan anggaran. Permendes (2016) tertulis tentang penggunaan dana desa, bahwa pada bagian kesatu bidang pembangunan desa, pasal 5 poin (b) dana desa dapat digunakan untuk pengadaan, pembangunan, pengembangan, dan pemeliharaan sarana prasarana pelayanan sosial dasar untuk pemenuhan kebutuhan kesehatan masyarakat, pendidikan dan kebudayaan. Selanjutnya, pada bagian kedua dalam Permendes (2016) pasal 7 poin (e) juga tertulis dana desa dapat digunakan untuk kegiatan pemberdayaan masyarakat. Kegiatan pemberdayaan masyarakat tersebut berupa kegiatan dukungan pengelolaan kegiatan pelayanan sosial dasar di bidang pendidikan, kesehatan, pemberdayaan perempuan dan anak, serta pemberdayaan masyarakat marginal dan anggota masyarakat Desa penyandang disabilitas.

Dasar hukum lain yang dapat digunakan sebagai landasan dalam penyelenggaraan Posbindu-PTM adalah sebagai berikut :
1. Kepmenkes RI Nomor 564/Menkes/SK/VIII/2006 tentang Pedoman Pelaksanaan Pengembangan Desa Siaga. 
2. Peraturan Menteri Kesehatan RI Nomor 741/Menkes / Per /VII/ 2008 tentang Standar Pelayanan Minimal Bidang Kesehatan di Kabupaten / Kota.

3. Undang-undang Nomor 36 Tahun 2009 tentang Kesehatan.

4. Keputusan menteri Kesehatan RI Nomor 374 / Menkes / SK / V / 2009 Tahun 2009 tentang Sistem Kesehatan Nasional.

5. Keputusan Menteri Kesehatan RI Nomor 1529 / Menkes / SK / X / 2010 Tahun 2010 tentang Pedoman Umum Penyelenggaraan Desa dan Kelurahan Siaga Aktif

6. Undang-undang Nomor 6 Tahun 2014 tentang Desa

Setelah bersama mempelajari dasar hukum yang dapat dipakai, maka langkah selanjutnya menyampaikan semua konsep tersebut dalam musyarawah desa untuk di tetapkan dalam Rencana Anggaran Pendapatan dan Belanja Desa (RAPBDes). Desa Ngrowo pada tahun 2018 telah menganggarkan pembiayaan Posbindu-PTM dari siltap dana desa tahun 2017. Pembiayaan tersebut digunakan untuk kegiatan sosialisasi, pelatihan kader, honorarium kader, pengadaan sarana dan prasana PosbinduPTM selama satu tahun. Sarana dan prasarana Posbindu-PTM yang di penuhi oleh Desa Ngrowo diantara, meja, kursi, alat tulis dan buku register, KMS dan buku saku Posbindu-PTM, tensi meter digital, timbang badan IMT digital, alat cek gula darah, cek kolesterol, cek asam urat, test strip gula darah, test strip kolesterol, test strip asam urat, pengukur tinggi badan, pengukur lingkar perut, blood lancets, alcohol swabs.

Pembentukan dan pelatihan kader

Posbindu-PTM perlu dilakukan untuk mempersiapkan kemampuan kader baik secara pengetahuan maupun skill kader sebelum mengadakan Posbindu-PTM yang sesungguhnya kepada masyarakat. Nugroho (2008) mengatakan keaktifan kader dalam melaksanakan posyandu ditentukan oleh motivasi kader, dimana motivasi kader ini sangat dipengaruhi oleh kepercayaan diri kader. Untuk meningkatkan kepercayaan diri kader, maka kader perlu diberikan seminar dan pelatihan terkait bidang yang akan dilaksanakannya. Pembentukan kader Posbindu-PTM Desa Ngrowo ini bersumber dari kader kesehatan Desa Ngrowo yang sudah ada, yaitu 4 orang kader dari masingmasing dusun. Setelah terbentuk kader, barulah dilakukan pelatihan kader bersama tim dari Puskesmas Bangsal, tim pengabdian masyarakat STIKes Majapahit dan tenaga kesehatan yang ada di Desa Ngrowo. Materi pelatihan meliputi konsep penyakit tidak menular dan cara meminimalisir faktor risiko PTM, konsep sistem 5 meja pada PosbinduPTM, macam dan cara penggunaan alat yang akan digunakan dalam Posbindu - PTM. Setelah pembentukan dan pelatihan kader, Posbindu-PTM Desa Ngrowo oleh Kepala Desa secara resmi berikan nama PosbinduPTM Srikandi Desa Ngrowo.

Kartiningrum, dkk (2017) mengatakan Posbindu-PTM yang baik menggunakan sistem 5 meja. Pembagian tugas dalam tiap meja dapat di kelompokkan sebagi berikut :

1. Meja 1 dapat diisi oleh kader dengan kegiatan melakukan pendaftaran, pencatatan ke dalam buku induk dan buku saku.

2. Meja 2 juga dapat diisi oleh kader dengan kegiatan melakukan wawancara terkait biodata lengkap peserta Posbindu-PTM dan riwayat kesehatan baik keluarga maupun pribadi peserta.

3. Meja 3 dapat dilakukan oleh tenaga kesehatan atau kader terlatih dengan kegiatan pengukuran tinggi badan, berat badan, lingkar pinggang, tekanan darah dan indek masa tubuh.

4. Meja 4 diisi oleh tenaga kesehatan dengan kegiatan pemeriksaan biokimia sederhana yang meliputi pengukuran gula darah acak, kadar kolesterol dan kadar asam urat, dan jika sudah berkembang juga bisa dilakukan tes IVA untuk deteksi dini kanker servik.

5. Meja 5 diisi oleh tenaga kesehatan atau kader terlatih dengan kegiatan pendidikan kesehatan, konseling, dialog interaktif dan pemberian aktifitas fisik seperti senam bersama. 
Hasil dari pelaksanaan posbindu PTM di ketiga Dusun yang ada di Desa Ngrowo banyak di dapatkan masyarakat yang mengalami darah tinggi dan kolesterol tinggi dimana total dari peserta yang mengikuiti Posbindu-PTM ada 27 orang yang mengalami darah tinggi dan 23 orang kadar kolesterolnya tinggi. Kondisi ini dapat di sebabkan karena kebiasaan masyarakat dalam pola hidup sehat yang kurang. Hasil wawancara masyarakat Desa Ngrowo memiliki riwayat kesehatan keluarga penderita darah tinggi, banyak masyarakat yang suka makan asin dan kurang dalam melakukan olahraga yang rutin. Kemenkes RI (2012) menyampaikan faktor risiko yang dapat menyebabkan penyakit tidak menular di masyarakat lebih banyak disebabkan masyarakat masih banyak yang suka mengkonsumsi makan makanan yang tinggi garam atau asin lebih dari tiga kali makan makanan asin dalam sehari. Selain itu, masyarakat juga masih jarang berolah raga secara teratur minimal 3 kali dalam seminggu dengan durasi waktu olah raga minimal 30 menit dalam sekali olah raga. Masyarakat masih beranggapan bahwa kegiatan fisik harian mereka itu sama dengan olah raga karena sama-sama mengeluarkan keringat. Pada saat pelaksaan peserta perempuan Posbindu-PTM Srikandi Desa Ngrowo juga diberikan motivasi untuk mengikuti pemeriksaan IVA gratis yang diselenggarakan oleh IBI ranting STIKes Majapahit di Kampus STIKes Majapahit untuk deteksi dini terjadinya kanker servik. Berdasarkan hasil tersebut maka kegiatan Posbindu-PTM ini sangat perlu untuk di populerkan dalam masyarakat serta dikembangkan, agar nantinya masyarakat lebih paham tentang faktor risiko terjadinta PTM, dapat melakukan pengecekan secara rutin dan berkala serta mendapatkan pendidikan kesehatan secara baik

\section{SIMPULAN DAN SARAN}

Program Posbindu-PTM merupakan salah satu UKBM untuk meminimalkan faktor risiko PTM di masyarakat. Pembiayaan penyelenggaraan Posbindu-PTM di Desa dapat di anggarkan melalui Dana Desa oleh Kepala Desa melalui keputusan bersama dalam musyawarah Desa. Oleh karenanya, upaya advokasi terkait dasar hukum penggunaan dana desa ini perlu di tingkatkan agar lebih banyak lagi Kepala Desa lain yang turut serta membentuk Posbindu-PTM di Desanya masing-masing. Kader Posbindu-PTM perlu dibentukan kader tersendiri dari kader kesehatan yang sudah ada di Desa agar bisa lebih fokus dan terampil dalam melaksanakan PosbinduPTM.

\section{UCAPAN TERIMAKASIH}

Ucapan terimakasih disampaikan kepada Kepala Desa Ngrowo berserta seluruh aparatur pemerintah Desa Ngrowo, Kepala Puskesmas Bangsal, Kepala Dusun Tawangsari, Kepala Dusun Pendowo, Kepala Dusun Ngranggon, pendamping Desa Ngrowo, kader kesehatan Desa Ngrowo, tenaga kesehatan yang bertempat tinggal di Desa Ngrowo, tokoh agama dan tokoh masyarakat yang telah membantu terlaksananya kegiatan pengabdian masyarakat.

\section{DAFTAR PUSTAKA}

Badan Penelitian dan Pengembangan Kesehatan Kementerian Kesehatan RI. 2013. Riset Kesehatan Dasar RISKESDAS 2013. Jakarta: Badan Penelitian dan Pengembangan Kesehatan Kementerian Kesehatan RI

Kartiningrum, E. D., Puspitaningsih, D., Kusuma, Y. L. H., \& Megawati, V. N. (2017). Upaya pembinaan posbindu penyakit tidak menular (ptm) dusun glonggongan desa sumber tebu bangsal kabupaten mojokerto. Publikasi hasil penelitian, (1), 354-358.

Kementrian Kesehatan RI. 2012. Pedoman Umum Penyelenggaraan Pos Pembinaan Perpadu Penyakit Tidak Menular (Posbindu-PTM). Jakarta : Direktorat Jendral Pengendalian Penyakit Dan Penyehatan Lingkungan Direktorat Pengendalian Penyakit Tidak Menular.

Nisak, R., Maimunah, S., \& Admadi, T. (2018). Upaya pemberdayaan masyarakat melalui deteksi dini dan pengendalian penyakit degeneratif pada lansia di dsn. Karang pucang, ds. Ngancar, kec. Pitu wilayah kerja puskesmas pitu kabupaten ngawi. Jurnal 
Pengabdian Masyarakat Kesehatan, 4(1), 18-22.

Nugroho, H. A., \& Nurdiana, D. (2008). Hubungan antara pengetahuan dan motivasi kader posyandu dengan keaktifan kader posyandu di desa dukuh tengah kecamatan ketanggungan kabupaten brebes. FIKkeS, 2(1).

Umayana, H. T., \& Cahyati, W. H. (2015). Dukungan Keluarga Dan Tokoh Masyarakat Terhadap Keaktifan Penduduk ke Posbindu Penyakit Tidak Menular. Jurnal Kesehatan Masyarakat, 11(1), 96-101.

Pusat Data dan Informasi Kementrian Kesehatan RI. 2017. Data dan Informasi (Profil Kesehatan Indonesia 2016). Jakarta: Pusat Data dan Informasi Kementrian Kesehatan RI.

Puspitaningsih, D., \& Kusuma, Y. L. H. (2017). Diabetes mellitus, stres dan manajemen stres. E-book stikespoltekkes majapahit. 